\title{
Clinical features of carriers of reciprocal chromosomal translocations involving chromosome 2: report of nine cases and review of the literature
}

\author{
Xinyue Zhang ${ }^{1}$, Hongguo Zhang ${ }^{1}$, Cong Hu ${ }^{1}$, Ruixue Wang ${ }^{1}$, Qi Xi ${ }^{1}$, Ruizhi Liu ${ }^{1}$ \\ ${ }^{1}$ Center for Reproductive Medicine and Center for Prenatal Diagnosis, First Hospital, Jilin University, \\ Changchun, China
}

\section{ABSTRACT}

Objective: To explore the clinical features of carriers of chromosome 2 translocations, enabling informed genetic counseling of these patients.

Materials and Methods: Eighty-two male carriers of a translocation who were infertile or receiving fertility counseling were recruited. Cytogenetic analyses were performed using G-banding. A search of PubMed was performed to determine whether the identified translocations on chromosome 2 are involved in male infertility. The relationships of translocation breakpoints with male infertility and recurrent pregnancy loss were analyzed.

Results: Of the 82 translocation carriers, 9 (11\%) were carriers of a chromosome 2 translocation. Four cases had oligozoospermia or infertility, while five had normal semen. In an analysis of the literature, 55 patients who were carriers of chromosome 2 translocations were also reviewed. Breakpoints at 2 p13 and $2 q 31$ were observed in six patients each, and were the most common. Breakpoints at 2p23, 2p13, 2p11.2, 2q31, and 2 q37 were associated to both pre-gestational and gestational infertility, while other breakpoints were associated with gestational infertility.

Conclusions: All breakpoints at chromosome 2 were correlated with gestational infertility. Carriers of chromosome 2 translocations should therefore receive counseling to continue with natural conception and use of different technologies available via assisted reproductive technology, such as preimplantation genetic diagnosis.

\section{ARTICLE INFO}

\author{
Keywords: \\ Infertility, Male; Chromosomes, \\ Human, Pair 2; Genetic \\ Counseling
}

Int Braz J Urol. 2018; 44: 785-93

Submitted for publication:

April 10, 2017

Accepted after revision:

September 06, 2017

Published as Ahead of Print:

November 29, 2017

\section{INTRODUCTION}

Infertility affects approximately 15\%$20 \%$ of couples who attempt to have children. Reciprocal translocations are present in 0.9/1000 newborns, and the incidence in the infertile male population is 7-10 times higher than in fertile men $(1,2)$. Balanced translocation is the most common structural rearrangement in humans
(3). Chromosomal translocations may cause the loss of genetic material at the breakpoints and could result in testicular failure (4). Individuals affected by such translocations are associated with reproductive problems such as infertility, recurrent pregnancy loss, and malformed offspring (5). These effects are related to the specific chromosomes and breakpoints involved in the translocation $(6,7)$. Some translocation break- 
points can disrupt the structure of an important gene, leading to male infertility (8).

The genetic counseling of male carriers of translocations remains challenging. Preimplantation genetic diagnosis (PGD) is a recommended part of such counseling for those with balanced translocation with normal or abnormal semen. In vitro fertilization accompanied by PGD increases the chance of their fathering a healthy child (9). In azoospermia patients, pregnancy success and fertility may be achieved via intracytoplasmic sperm injection, using spermatozoa obtained from testis by microdissection testicular sperm extraction $(10,11)$.

However, De Krom et al. (12) reported that clinical characteristics including spontaneous abortion do not differ between those couples who accept and those who decline PGD. A systematic review also showed a lack of sufficient evidence that PGD improves the live birth rate in couples with repeated miscarriage carrying a structural chromosome abnormality (13). In addition, the natural pregnancy success rates for couples in which the male carries a translocation ranges from $30 \%$ to $70 \%$ (14). This suggests that continuing attempts to conceive naturally are a viable option for successful pregnancy. Hence, the relationship between chromosome structure abnormality and clinical features warrants further studies.

There may be important genes associated with spermatogenesis on chromosome 2. For example, follicle-stimulating hormone receptor (FSHR) is located on chromosome $2 \mathrm{p} 16.3$, and is expressed in testicular tissue of idiopathic azoospermic patients with severe spermatogenic defects. Its differential expression may be associated with the degree of spermatogenesis (15). A study has also shown that genetic polymorphisms in the FSHR gene might increase the susceptibility to azoospermia in Iranian men (16). However, the FSHR polymorphisms at the studied sites were shown not to be associated with idiopathic male infertility or to influence FSH levels in both normal and infertile males in the Han-Chinese population (17). In addition, the SPAG16 gene (sperm-associated antigen 16), mapped on chromosome 2 at 2q34, has been reported to be associated with impaired sperm motility (18). The breakpoints of 2q25.1, q11.2, and q31 have also been shown to be related to impaired spermatogenesis (19).
The present study was established to explore the clinical features and translocation breakpoints in carriers of reciprocal chromosomal translocations involving chromosome 2. This study also highlights the importance of genetic counseling for infertile patients.

\section{MATERIALS AND METHODS}

\section{Study subjects}

Between July 2010 and December 2015, we recruited 82 male carriers of translocations experiencing infertility, or receiving counseling, from the outpatient's department at the Centre for Reproductive Medicine, the First Hospital of Jilin University, Changchun, China. All patients underwent a thorough physical examination and semen analysis, and were required to complete a detailed questionnaire pertaining to their smoking habits, marital status, medical history, and working conditions. The study protocol was approved by the Ethics Committee of the First Hospital of Jilin University, and written informed consent was obtained from all participants.

\section{Semen analysis}

Semen analysis was performed according to the procedures recommended by the World Health Organization guideline. If no sperm was found, sperm was analyzed by sedimentation of semen samples through centrifugation. Patients with oligozoospermia were diagnosed as a sperm cell count $<15 \times 10^{6} / \mathrm{mL}$ in their last 3 semen samples (taken at intervals of 1-3 weeks). Azoospermia and oligozoospermia were defined as previously described (8). All analyzes were performed at the same laboratory, and all data were accessed from medical records.

\section{Cytogenetic analysis}

Cytogenetic analysis was carried out on all patients. Peripheral blood $(0.5 \mathrm{~mL})$ was collected in sterile tubes containing $30 \mathrm{U} / \mathrm{mL}$ heparin. Lymphocytes were then cultured in appropriate culture medium (Yishengjun; Guangzhou Baidi Biotech, Guangzhou, China) for $72 \mathrm{~h}$, and subsequently treated with colcemid for $1 \mathrm{~h}$. G-banding of metaphase chromosomes and karyotype analysis were 
performed using previously described methods (20). Twenty metaphases were counted and 6 karyotypes were analyzed for per patient. The karyotype nomenclature was described in accordance of ISCN 2009. The resolution level of the chromosome analysis was $400-550$ band levels.

Analysis of the identified translocation breakpoints

A search for the translocations identified in chromosome 2 from infertile males was performed using PubMed. The keywords were "chromosome/ translocation/sperm" and "chromosome/translocation/abortion" for Pubmed search. The criteria were that the patients included reciprocal chromosomal translocations involving chromosome 2 in reported papers. The relationships of translocation breakpoints with male infertility and recurrent pregnancy loss were analyzed. Such searches were performed for a total of 46 carriers of chromosomal 2 translocations. This study included the cases of reciprocal chromosomal translocations involving chromosome 2 in reported papers and excluded the cases without breakpoints involving chromosome 2 .

\section{RESULTS}

A total of 82 translocation carriers were detected in this study. Of these, nine (11\%) were carriers of a chromosome 2 translocation. Karyotype results from these nine patients are summarized in Table-1. Four cases had oligozoospermia or infertility (pre-gestational infertility), while five cases had normal semen. Of these latter five cases, it was evident that their partners were able to conceive, but had a tendency to miscarry (gestational infertility): one case had experienced recurrent spontaneous abortions, one case had experienced two stillbirths, and one case had experienced biochemical pregnancy on three occasions, while two cases produced a phenotypically normal child.

An analysis of the literature was also performed, from which karyotype results, clinical manifestations, and the breakpoints on chromosome 2 were collected, as shown in Table-2. Breakpoints at $2 p 13$ and $2 q 31$ were observed in six patients each, and were the most common. Breakpoints at q10 and q11.2 were related to pre-gestational infertility, while breakpoints at 2p23, 2p13, 2p11.2, 2q31, and $2 \mathrm{q} 37$ were connected to both pre-gestational and gestational infertility. Other breakpoints were associated with gestational infertility. It is noteworthy that two carriers of a translocation at 2 q33 produced normal children, as did one carrier of a translocation at 2q35 (Table-3).

\section{DISCUSSION}

Karyotype analysis is able to detect chromosomal translocations or deletions, which sometimes have very detrimental effects on gene structure, and remains a powerful and cheap method to use (21). This technology thus provides valuable information for the genetic counseling of infertile males (22). Previous studies have reported that infertile men have an 8-10-fold higher prevalence of

Table 1 - Karyotypes of chromosome 2 translocation carriers and their clinical features.

\begin{tabular}{|c|c|c|}
\hline Infertility causes & Clinical findings & Karyotype \\
\hline Pre-gestational infertility & Oligozoospermia or infertility & $\begin{array}{c}46, \mathrm{XY}, \mathrm{t}(1 ; 2)(\mathrm{q} 21 ; \mathrm{p} 23) \\
46, \mathrm{XY}, \mathrm{t}(1 ; 2)(\mathrm{q} 21 ; \mathrm{q} 37) \\
46, \mathrm{XY}, \mathrm{t}(2 ; 13)(\mathrm{q} 10 ; \mathrm{q} 10) \\
46, \mathrm{XY}, \mathrm{t}(2 ; 15)(\mathrm{p} 11.2 ; \mathrm{q} 15)\end{array}$ \\
\hline Gestational infertility & $\begin{array}{l}\text { Normal sperm density; a history of miscarriage, } \\
\text { stillbirth, or normal fertility }\end{array}$ & $\begin{array}{c}46, \mathrm{XY}, \mathrm{t}(2 ; 6)(\mathrm{q} 21 ; \mathrm{p} 21) \\
46, \mathrm{XY}, \mathrm{t}(2 ; 11)(\mathrm{q} 33 ; \mathrm{q} 23) \\
46, \mathrm{XY}, \mathrm{t}(2 ; 11)(\mathrm{q} 35 ; \mathrm{q} 13) \\
46, \mathrm{XY}, \mathrm{t}(2 ; 14)(\mathrm{q} 31 ; \mathrm{q} 24) \\
46, \mathrm{XY}, \mathrm{t}(2 ; 16)(\mathrm{p} 23 ; \mathrm{q} 13)\end{array}$ \\
\hline
\end{tabular}


Table 2 - Breakpoints in chromosome 2 translocation carriers and clinical features.

\begin{tabular}{|c|c|c|c|c|}
\hline Case & Karyotype & Breakpoints & Clinical findings & Reference \\
\hline 1 & $t(1 ; 2)$ & $1 p 22 ; 2 q 31$ & 2 miscarriages & Dong et al., 2014 (31) \\
\hline 2 & $t(1 ; 2)$ & $1 q 21 ; 2 p 23$ & Oligozoospermia & The present study \\
\hline 3 & $t(1 ; 2)$ & $1 q 21 ; 2 q 37$ & Oligozoospermia & The present study \\
\hline 4 & $t(1 ; 2)$ & $1 q 21 ; 2 q 37$ & Oligozoospermia & Li et al., 2012 (23) \\
\hline 5 & $t(1 ; 2)$ & $1 q 32 ; 2 q 36$ & Abortion & Templado et al., 1990 (32) \\
\hline 6 & $t(1 ; 2)$ & $1 q 32.1 ; 2 q 11.2$ & Oligozoospermia & Vozdova et al., 2013 (9) \\
\hline 7 & $t(1 ; 2)$ & $1 q 42 ; 2 q 37$ & 2 fetal malformations & Zhang et al., 2006 (33) \\
\hline 8 & $t(1 ; 2)$ & $1 q 42 ; 2 q 33$ & Miscarriage & $\begin{array}{l}\text { Stasiewicz-Jarocka et al., } \\
2000(34)\end{array}$ \\
\hline 9 & $t(2 ; 3)$ & $2 p 13 ; 3 q 27$ & Recurrent pregnancy loss & Ocak et al., 2013 (35) \\
\hline 10 & $t(2 ; 3)$ & $2 q 21 ; 3 p 21$ & Recurrent spontaneous abortion & Tunç et al., 2016 (26) \\
\hline 11 & $\mathrm{t}(2 ; 3)$ & $2 q 24 ; 3 p 26)$ & Normal semen & Martin, 1994 (36) \\
\hline 12 & $\mathrm{t}(2 ; 4)$ & $2 p 21 ; 4 p 14$ & Recurrent abortion & Portnoï et al., 1988 (37) \\
\hline 13 & $\mathrm{t}(2 ; 4)$ & $2 q 31 ; 4 q 31$ & Stillbirth & Li et al., 2012 (23) \\
\hline 14 & $\mathrm{t}(2 ; 4)$ & $2 q 31 ; 4 q 31$ & 2 stillbirths & Dong et al., 2014 (31) \\
\hline 15 & $t(2 ; 5)$ & $2 p 21 ; 5 p 15$ & Recurrent spontaneous abortion & $\begin{array}{l}\text { Gada Saxena et al., } 2012 \\
\text { (25) }\end{array}$ \\
\hline 16 & $t(2 ; 5)$ & $2 p 13 ; 5 p 15$ & Recurrent fetal wastage & Fryns et al., 1998 (38) \\
\hline 17 & $t(2 ; 5)$ & $2 \mathrm{p} 11 ; 5 \mathrm{q} 15$ & Abortion & Templado et al., 1988 (39) \\
\hline 18 & $t(2 ; 5)$ & $2 p 11 ; 5 q 31$ & Recurrent abortion & Portnoï et al., 1988 (37) \\
\hline 19 & $t(2 ; 5)$ & $2 q 12 ; 5 q 35.3$ & Spontaneous miscarriage & Kochhar et al., 2013 (40) \\
\hline 20 & $\mathrm{t}(2 ; 6)$ & 2p13;6p21.3 & Recurrent abortion & Al-Hussain et al., 2000 (41) \\
\hline 21 & $\mathrm{t}(2 ; 6)$ & $2 \mathrm{p} 12 ; 6 \mathrm{q} 24$ & Two earlier miscarriages & Lim et al., 2003 (42) \\
\hline 22 & $\mathrm{t}(2 ; 6)$ & $2 q 21 ; 6 p 21$ & 3 first-trimester abortions & The present study \\
\hline 23 & $\mathrm{t}(2 ; 6)$ & $2 q 34 ; 6 p 24$ & Recurrent spontaneous abortion & $\begin{array}{c}\text { Gada Saxena et al., } 2012 \\
(25)\end{array}$ \\
\hline 24 & $\mathrm{t}(2 ; 7)$ & $2 p 23 ; 7 p 22$ & Recurrent fetal wastage & Fryns et al., 1998 (38) \\
\hline 25 & $\mathrm{t}(2 ; 7)$ & $2 p 13 ; 7 q 34$ & $\begin{array}{l}\text { Normal semen, IVF/PGD ET, twins } \\
46, \mathrm{XX}\end{array}$ & Vozdova et al., 2013 (9) \\
\hline 26 & $\mathrm{t}(2 ; 7)$ & $2 p 13 ; 7 q 32$ & $\begin{array}{c}\text { Primary infertility, abnormal } \\
\text { semen }\end{array}$ & Vozdova et al., 2013 (9) \\
\hline 27 & $\mathrm{t}(2 ; 7)$ & $2 q 31 ; 7 q 34$ & Abnormal semen & Vozdova et al., 2013 (9) \\
\hline 28 & $\mathrm{t}(2 ; 7)$ & $2 \mathrm{p} 11.2 ; 7 \mathrm{q} 22.1$ & 2 miscarriages & Wiland et al., 2008 (3) \\
\hline 29 & $\mathrm{t}(2 ; 7)$ & 2q37.3;7q34) & 3 miscarriages & Ahn et al., 2003 (43) \\
\hline 30 & $t(2 ; 8)$ & $2 p 13 ; 8 q 13$ & Multiple spontaneous abortions & Castle et al., 1988 (44) \\
\hline 31 & $\mathrm{t}(2 ; 8)$ & $2 p 22 ; 8 p 23.1$ & Spontaneous abortions & Kyu Lim et al., 2004 (45) \\
\hline
\end{tabular}




\begin{tabular}{|c|c|c|c|c|}
\hline 32 & $\mathrm{t}(2 ; 8)$ & $2 q 35 ; 8 q 11.2$ & Spontaneous abortions & Kyu Lim et al., 2004 (45) \\
\hline 33 & $\mathrm{t}(2 ; 8)$ & $2 q 37 ; 8 q 22$ & 3 abortions & Campana et al., 1986 (46) \\
\hline 34 & $\mathrm{t}(2 ; 9)$ & $2 q 21 ; 9 p 22$ & Abortion & Martin et al., 1990 (47) \\
\hline 35 & $\mathrm{t}(2 ; 9)$ & $2 q 37.3 ; 9 q 12$ & $\begin{array}{l}\text { Normal semen, increased risk of } \\
\text { miscarriage }\end{array}$ & Dul et al., 2012 (48) \\
\hline 36 & $\mathrm{t}(2 ; 10)$ & $2 q 33 ; 10 q 24$ & Produced a child, 46,XX & Faed et al., 1982 (49) \\
\hline 37 & $\mathrm{t}(2 ; 11)$ & $2 p 14 ; 11 q 21$ & Repeated abortion & Ananthapur et al., 2014 (5) \\
\hline 38 & $\mathrm{t}(2 ; 11)$ & $2 q 24 ; 11 q 32$ & Recurrent abortion & Al-Hussain et al., 2000 (41) \\
\hline 39 & $t(2 ; 11)$ & $2 q 33 ; 11 q 23$ & Produced a child, 46,XX & The present study \\
\hline 40 & $t(2 ; 11)$ & $2 q 35 ; 11 q 13$ & Produced a child, 46,XX,t(2;11) & The present study \\
\hline 41 & $\mathrm{t}(2 ; 12)$ & $2 q 31 ; 12 q 24$ & 3 first-trimester abortions & Niroumanesh et al., 2011 (50) \\
\hline 42 & $t(2 ; 13)$ & $2 q 35 ; 13 q 32$ & Repeated miscarriage & Goddijn et al., 2004 (51) \\
\hline 43 & $t(2 ; 13)$ & $2 q 10 ; 13 q 10$ & Oligozoospermia & The present study \\
\hline 44 & $\mathrm{t}(2 ; 14)$ & $2 p 23.1 ; 14 q 31$ & Abortion & Rousseaux et al., 1995 (52) \\
\hline 45 & $t(2 ; 14)$ & $2 q 12 ; 14 q 32.33$ & Recurrent spontaneous abortion & Manvelyan et al., 2007 (27) \\
\hline 46 & $\mathrm{t}(2 ; 14)$ & $2 q 31 ; 14 q 24$ & 2 stillbirths & The present study \\
\hline 47 & $t(2 ; 14)$ & $2 q 37.1 ; 14 q 31.2$ & Fetal malformations & de la Fuente et al., 1988 (53) \\
\hline 48 & $\mathrm{t}(2 ; 15)$ & $2 p 11.2 ; 15 q 15$ & Infertility & The present study \\
\hline 49 & $t(2 ; 15)$ & $2 q 21 ; 15 p 12$ & Recurrent fetal wastage & Fryns et al., 1998 (38) \\
\hline 50 & $\mathrm{t}(2 ; 16)$ & $2 p 23 ; 16 q 13$ & Recurrent spontaneous abortion & The present study \\
\hline 51 & $\mathrm{t}(2 ; 17)$ & $2 q 35 ; 17 p 13$ & Abortion & Jenderny, 1992 (54) \\
\hline 52 & $\mathrm{t}(2 ; 17)$ & $2 q 37.2 ; 17 q 25$ & Recurrent spontaneous abortion & Bruyere et al., 2003 (55) \\
\hline 53 & $t(2 ; 18)$ & $2 p 21 ; 18 q 11.2$ & 5 miscarriages & Estop et al., 1995 (56) \\
\hline 54 & $\mathrm{t}(2 ; 20)$ & $2 p 16 ; 20 p 12$ & Recurrent abortion & Sachs et al., 1985 (57) \\
\hline 55 & $t(2 ; 20)$ & 2p24.1;20q13.1 & Recurrent abortion & Trappe et al., 2002 (58) \\
\hline
\end{tabular}

chromosomal abnormalities than fertile men (23). Chromosomal translocation alters the complex and vital process of spermatogenesis, and leads to recurrent pregnancy loss (24). In particular, chromosome 2 translocation has often been associated with male infertility and recurrent miscarriage $(9$, $25,26)$. In the present study, nine of our cases were identified as carriers of chromosome 2 translocations, and 55 cases of chromosome 2 translocation from the literature were also reviewed.

Generally, male infertility can be broadly divided into two types of reproductive failure: pre-gestational and gestational infertility (23). In this study, the breakpoints that we identified on chromosome 2 were found to be associated with pre-gestational or gestational infertility. Four cases were associated with pre-gestational infertility and five cases were related to gestational infertility. Kim et al. (19) reported that the breakpoints at 2p25.1, $2 q 11.2$, and $2 q 31$ could interfere with spermatogenesis, and that the breakpoint at $2 \mathrm{p} 13$ was related to recurrent abortion. In addition, Manvelyan et al. (27) reported that the breakpoint at 2 q12 in male carriers was associated with repeated abortion. To study the relationship of these breakpoints on chromosome 2 with male infertility, we analyzed recent 
Table 3 - Incidence of breakpoints on chromosome 2.

\begin{tabular}{|c|c|c|c|}
\hline Breakpoints & $\begin{array}{l}\text { Number of patients with } \\
\text { pre-gestational infertility }\end{array}$ & $\begin{array}{l}\text { Number of patients with } \\
\text { gestational infertility }\end{array}$ & Reproductive outcomes \\
\hline p24.1 & & 1 & \\
\hline p23.1 & & 1 & \\
\hline p23 & 1 & 2 & \\
\hline p22 & & 1 & \\
\hline p21 & & 3 & \\
\hline p16 & & 1 & \\
\hline p14 & & 1 & \\
\hline p13 & 1 & 4 & $\begin{array}{c}1 \text { case of IVF/PGD ET, twins } \\
46, X X\end{array}$ \\
\hline p12 & & 1 & \\
\hline p11.2 & 1 & 1 & \\
\hline p11 & & 2 & \\
\hline$q 10$ & 1 & & \\
\hline $\mathrm{q} 11.2$ & 1 & & \\
\hline$q 12$ & & 2 & \\
\hline q21 & & 4 & \\
\hline q24 & & 2 & \\
\hline q31 & 1 & 5 & \\
\hline q33 & & 1 & $\begin{array}{c}2 \text { cases of natural pregnancy, } \\
\text { birth } 46, X X\end{array}$ \\
\hline q34 & & 1 & \\
\hline q35 & & 3 & $\begin{array}{c}1 \text { case of natural pregnancy, } \\
\text { birth } 46, X X, t(2 ; 11)\end{array}$ \\
\hline q36 & & 1 & \\
\hline q37 & 2 & 2 & \\
\hline q37.1 & & 1 & \\
\hline q37.2 & & 1 & \\
\hline q37.3 & & 2 & \\
\hline p24.1 & & 1 & \\
\hline
\end{tabular}

published literature and revealed clinical features in carriers of chromosome 2 translocations. The karyotype results and clinical findings at chromosome 2 are summarized in Table-2. Clinical features associated with the breakpoints at $2 p 13$, $2 q 11.2$, and $2 q 12$ were consistent with the above two reports $(19,27)$.

Table-3 also shows that 2p23, 2p13, $2 \mathrm{p} 11.2,2 \mathrm{q} 31$, and $2 \mathrm{q} 37$ were connected to both pre-gestational and gestational infertility. These cases indicated that these breakpoints are not responsible for pre-gestational infertility, so another breakpoint of translocation must be the cause in these individuals. Similarly, the APOB gene is located on chromosome $2 \mathrm{p} 24.1$, and the APOB gene signal peptide deletion polymorphism was reported not to be associated with infertility in Indian men (28). Furthermore, FSHR, mapped on chromosome 2 at $2 \mathrm{p} 16$, was shown not to be correlated with sperm count in infertile males (29). 
Besides the breakpoints at q10 and q11.2, other breakpoints were identified as being associated with gestational infertility. For those affected by these breakpoints, natural conception is possible and they have the potential to bear normal children. For example, Ikuma et al. (30) reported that the live birth rate with natural conception for translocation carriers was 37\%-63\% in the first trial and 65\%-83\% cumulatively. However, natural conception is still a greater risk, since the number of chromosomal unbalanced gametes is large, leading to repetitive pregnancy loss, which may have repercussions on the fertility of the translocation carrier. For these carriers, informed choice should be performed. In addition, the breakpoints at $2 \mathrm{p} 13$ and 2 q31 were found to be the most common, and were associated with gestational infertility.

\section{CONCLUSIONS}

In the present study, 55 carriers of chromosome 2 translocations were reviewed. The breakpoints at 2 p13 and $2 q 31$ were the most common, and were associated with gestational infertility. All breakpoints at chromosome 2 were correlated with gestational infertility. Carriers of chromosome 2 translocations should therefore be counselled to attempt natural conception and to use the different technologies available via assisted reproductive technology, such as PGD.

\section{ABBREVIATIONS}

PGD = Preimplantation genetic diagnosis

FSH $=$ Follicle-stimulating hormone

FSHR = Follicle-stimulating hormone receptor

SPAG 16 gene $=$ Sperm-associated antigen 16 gene APOB gene $=$ Apolipoprotein $\mathrm{B}$ gene

\section{ACKNOWLEDGEMENTS}

This study was supported by grants from the National Natural Science Foundation of China (81471515).

\section{CONFLICT OF INTEREST}

None declared.

\section{REFERENCES}

1. Mafra FA, Christofolini DM, Bianco B, Gava MM, Glina $\mathrm{S}$, Belangero SI, et al. Chromosomal and molecular abnormalities in a group of Brazilian infertile men with severe oligozoospermia or non-obstructive azoospermia attending na infertility service. Int Braz J Urol. 2011;37:24450; discussion 250-1.

2. Hotaling J, Carrell DT. Clinical genetic testing for male factor infertility: current applications and future directions. Andrology. 2014;2:339-50.

3. Wiland E, Hobel CJ, Hill D, Kurpisz M. Successful pregnancy after preimplantation genetic diagnosis for carrier of $\mathrm{t}(2 ; 7)$ (p11.2;q22) with high rates of unbalanced sperm and embryos: a case report. Prenat Diagn. 2008;28:36-41.

4. Song SH, Chiba K, Ramasamy R, Lamb DJ. Recent advances in the genetics of testicular failure. Asian $\mathrm{J}$ Androl. 2016;18:350-5.

5. Ananthapur V, Avvari S, Veena K, Sujatha M, Jyothy A. Non-Robertsonian translocation $t(2 ; 11)$ is associated with infertility in an oligospermic man. Andrologia. 2014;46:453-5.

6. Godo A, Blanco J, Vidal F, Anton E. Accumulation of numerical and structural chromosome imbalances in spermatozoa from reciprocal translocation carriers. Hum Reprod. 2013;28:840-9.

7. Harton GL, Tempest HG. Chromosomal disorders and male infertility. Asian J Androl. 2012;14:32-9.

8. Zhang HG, Wang RX, Li LL, Sun WT, Zhang HY, Liu RZ. Male carriers of balanced reciprocal translocations in Northeast China: sperm count, reproductive performance, and genetic counseling. Genet Mol Res. 2015;14:18792-8.

9. Vozdova M, Oracova E, Kasikova K, Prinosilova P, Rybar R, Horinova V, et al. Balanced chromosomal translocations in men: relationships among semen parameters, chromatin integrity, sperm meiotic segregation and aneuploidy. J Assist Reprod Genet. 2013;30:391-405.

10. Povlsen BB, Aw LD, Laursen RJ, Esteves SC, Humaidan P. Pregnancy and birth after intracytoplasmic sperm injection with normal testicular spermatozoa in a patient with azoospermia and tail stump epididymal sperm. Int Braz J Urol. 2015;41:1220-5.

11. Vloeberghs V, Verheyen $G$, Haentjens $P$, Goossens $A$, Polyzos NP, Tournaye H. How successful is TESE-ICSI in couples with non-obstructive azoospermia? Hum Reprod. 2015;30:1790-6.

12. De Krom G, Arens YH, Coonen E, Van Ravenswaaij-Arts CM, Meijer-Hoogeveen M, Evers JL, Van Golde RJ, et al. Recurrent miscarriage in translocation carriers: no differences in clinical characteristics between couples who accept and couples who decline PGD. Hum Reprod. 2015;30:484-9. 
13. Franssen MT, Musters AM, van der Veen F, Repping S, Leschot $\mathrm{NJ}$, Bossuyt PM, et al. Reproductive outcome after PGD in couples with recurrent miscarriage carrying a structural chromosome abnormality: a systematic review. Hum Reprod Update. 2011;17:467-75.

14. Ozawa N, Maruyama T, Nagashima T, Ono M, Arase T, Ishimoto $\mathrm{H}$, et al. Pregnancy outcomes of reciprocal translocation carriers who have a history of repeated pregnancy loss. Fertil Steril. 2008;90:1301-4.

15. Wang L, Huang H, Jin F, Zhou C, Qian Y, Chen J. High expression of follicle stimulating hormone receptor in testicular tissue of idiopathic azoospermic patients with severe spermatogenic defects. Chin Med J (Engl). 2014;127:488-93.

16. Gharesi-Fard B, Ghasemi Z, Shakeri S, Behdin S, Aghaei F, Malek-Hosseini Z. The frequency of follicle stimulating hormone receptor gene polymorphisms in Iranian infertile men with azoospermia. Iran J Reprod Med. 2015;13:673-8.

17. Li Y, Gu A, Yang H, Ding X, Ji G, Lu C, et al. FSH receptor gene polymorphisms in fertile and infertile Han-Chinese males. Clin Chim Acta. 2011;412:1048-52.

18. Zhang Z, Kostetskii I, Tang W, Haig-Ladewig L, Sapiro R, Wei Z, et al. Deficiency of SPAG16L causes male infertility associated with impaired sperm motility. Biol Reprod. 2006;74:751-9.

19. Kim JW, Chang EM, Song SH, Park SH, Yoon TK, Shim SH. Complex chromosomal rearrangements in infertile males: complexity of rearrangement affects spermatogenesis. Fertil Steril. 2011;95:349-52, 352.e1-5.

20. Zhang HG, Liu XY, Hou Y, Chen S, Deng S, Liu RZ. Reproductive outcome of a case with familial balanced translocation $t(3 ; 6)$ : implications for genetic counseling. Genet Mol Res. 2015;14:2809-15.

21. Pasquier L, Fradin M, Chérot E, Martin-Coignard D, Colin E, Journel $\mathrm{H}$, et al. Karyotype is not dead (yet)! Eur J Med Genet. 2016;59:11-5.

22. Poli MN, Miranda LA, Gil ED, Zanier GJ, Iriarte PF, Zanier JH, et al. Male cytogenetic evaluation prior to assisted reproduction procedures performed in Mar del Plata, Argentina. JBRA Assist Reprod. 2016;20:62-5.

23. Li D, Zhang H, Wang R, Zhu H, Li L, Liu R. Chromosomal abnormalities in men with pregestational and gestational infertility in northeast China. J Assist Reprod Genet. 2012;29:829-36.

24. Stouffs K, Seneca S, Lissens W. Genetic causes of male infertility. Ann Endocrinol (Paris). 2014;75:109-11.

25. Gada Saxena S, Desai K, Shewale L, Ranjan P, Saranath D. Chromosomal aberrations in 2000 couples of Indian ethnicity with reproductive failure. Reprod Biomed Online. 2012;25:209-18.

26. Tunç E, Tanrıverdi N, Demirhan O, Süleymanova D, Çetinel N. Chromosomal analyses of 1510 couples who have experienced recurrent spontaneous abortions. Reprod Biomed Online. 2016;32:414-9.
27. Manvelyan M, Schreyer I, Höls-Herpertz I, Köhler S, Niemann $\mathrm{R}$, Hehr U, et al. Forty-eight new cases with infertility due to balanced chromosomal rearrangements: detailed molecular cytogenetic analysis of the 90 involved breakpoints. Int $\mathrm{J}$ Mol Med. 2007;19:855-64.

28. Khattri A, Pandey RK, Gupta NJ, Chakravarty B, Deenadayal $M$, Singh $L$, et al. APOB gene signal peptide deletion polymorphism is not associated with infertility in Indian men. J Androl. 2009;30:734-8.

29. Ghirelli-Filho M, Peluso C, Christofolini DM, Gava MM, Glina S, Barbosa $\mathrm{CP}$, et al. Variants in follicle-stimulating hormone receptor gene in infertile Brazilian men and the correlation to FSH serum levels and sperm count. Reprod Sci. 2012;19:733-9.

30. Ikuma S, Sato T, Sugiura-Ogasawara M, Nagayoshi M, Tanaka A, Takeda S. Preimplantation Genetic Diagnosis and Natural Conception: A Comparison of Live Birth Rates in Patients with Recurrent Pregnancy Loss Associated with Translocation. PLoS One. 2015;10:e0129958.

31. Dong Y, Li LL, Wang RX, Yu XW, Yun X, Liu RZ. Reproductive outcomes in recurrent pregnancy loss associated with a parental carrier of chromosome abnormalities or polymorphisms. Genet Mol Res. 2014;13:2849-56.

32. Templado C, Navarro J, Requena R, Benet J, Ballesta F, Egozcue J. Meiotic and sperm chromosome studies in a reciprocal translocation $\mathrm{t}(1 ; 2)(\mathrm{q} 32 ; \mathrm{q} 36)$. Hum Genet. 1990;84:159-62.

33. Zhang YP, Xu JZ, Yin M, Chen MF, Ren DL. [Pregnancy outcomes of 194 couples with balanced translocations]. Zhonghua Fu Chan Ke Za Zhi. 2006;41:592-6.

34. Stasiewicz-Jarocka B, Raczkiewicz B, Kowalczyk D, Zawada M, Midro AT. Genetic risk of families with $t(1 ; 2)(q 42 ; q 33)$ GTG, RHG, QFQ, FISH. Ginekol Pol. 2000;71:1262-72. Erratum in: Ginekol Pol 2001;72:54.

35. Ocak Z, Özlü T, Ozyurt 0. Association of recurrent pregnancy loss with chromosomal abnormalities and hereditary thrombophilias. Afr Health Sci. 2013;13:447-52.

36. Martin RH. Sperm chromosome complements in a man heterozygous for a reciprocal translocation $\mathrm{t}(2 ; 3)(\mathrm{q} 24 ; \mathrm{p} 26)$. Hum Reprod. 1994;9:1512-5.

37. Portnoï MF, Joye N, van den Akker J, Morlier G, Taillemite JL. Karyotypes of 1142 couples with recurrent abortion. Obstet Gynecol. 1988;72:31-4.

38. Fryns JP, Van Buggenhout G. Structural chromosome rearrangements in couples with recurrent fetal wastage. Eur J Obstet Gynecol Reprod Biol. 1998;81:171-6.

39. Templado C, Navarro J, Benet J, Genescà A, Pérez MM, Egozcue J. Human sperm chromosome studies in a reciprocal translocation t(2;5). Hum Genet. 1988;79:24-8.

40. Kochhar PK, Ghosh P. Reproductive outcome of couples with recurrent miscarriage and balanced chromosomal abnormalities. J Obstet Gynaecol Res. 2013;39:113-20. 
41. Al-Hussain M, Al-Nuaim L, Abu Talib Z, Zaki OK. Cytogenetic study in cases with recurrent abortion in Saudi Arabia. Ann Saudi Med. 2000;20:233-6.

42. Lim AS, Lim TH, Kee SK, Chieng R, Tay SK. Sperm segregation patterns by fluorescence in situ hybridization studies of a $46, \mathrm{XY}, \mathrm{t}(2 ; 6)$ heterozygote giving rise to a rare triploid product of conception with a $69, \mathrm{XXY}, \mathrm{t}(2 ; 6)(\mathrm{p} 12 ; \mathrm{q} 24)$ $\operatorname{der}(6) t(2 ; 6)(p 12 ; q 24)$ pat karyotype. Am J Med Genet A. 2003;117A:172-6.

43. Ahn JM, Koo DH, Kwon KW, Lee YK, Lee YH, Lee HH, et al. Partial trisomy 2q(2q37.3-->qter) and monosomy $7 q(7 q 34-$ -->qter) due to paternal reciprocal translocation 2;7: a case report. J Korean Med Sci. 2003;18:112-3.

44. Castle D, Bernstein R. Cytogenetic analysis of 688 couples experiencing multiple spontaneous abortions. Am J Med Genet. 1988;29:549-56.

45. Kyu Lim C, Hyun Jun J, Mi Min D, Lee HS, Young Kim J, Koong MK, et al. Efficacy and clinical outcome of preimplantation genetic diagnosis using FISH for couples of reciprocal and Robertsonian translocations: the Korean experience. Prenat Diagn. 2004;24:556-61.

46. Campana M, Serra A, Neri G. Role of chromosome aberrations in recurrent abortion: a study of 269 balanced translocations. Am J Med Genet. 1986;24:341-56.

47. Martin RH, Barclay L, Hildebrand K, Ko E, Fowlow SB. Cytogenetic analysis of 400 sperm from three translocation heterozygotes. Hum Genet. 1990;86:33-9.

48. Dul EC, van Echten-Arends J, Groen H, Dijkhuizen T, Land $\mathrm{JA}$, van Ravenswaaij-Arts CM. Chromosomal abnormalities in azoospermic and non-azoospermic infertile men: numbers needed to be screened to prevent adverse pregnancy outcomes. Hum Reprod. 2012;27:2850-6.

49. Faed MJ, Lamont MA, Baxby K. Cytogenetic and histological studies of testicular biopsies from subfertile men with chromosome anomaly. J Med Genet. 1982;19:49-56.

50. Niroumanesh S, Mehdipour P, Farajpour A, Darvish S. A cytogenetic study of couples with repeated spontaneous abortions. Ann Saudi Med. 2011;31:77-9.

51. Goddijn M, Joosten JH, Knegt AC, van derVeen F, Franssen MT, Bonsel GJ, Let al. Clinical relevance of diagnosing structural chromosome abnormalities in couples with repeated miscarriage. Hum Reprod. 2004;19:1013-7.
52. Rousseaux S, Chevret E, Monteil M, Cozzi J, Pelletier R, Devillard $F$, et al. Meiotic segregation in males heterozygote for reciprocal translocations: analysis of sperm nuclei by two and three colour fluorescence in situ hybridization. Cytogenet Cell Genet. 1995;71:240-6.

53. de la Fuente AA, Gerssen-Schoorl KB, Breed AS. Partial duplication $14 \mathrm{q}$ /deletion $2 \mathrm{q}$ in two sibs due to $\mathrm{t}(2 ; 14)$ (q37.1;q31.2) pat. Ann Genet. 1988;31:254-7.

54. Jenderny J. Sperm chromosome analysis of two males heterozygous for a $\mathrm{t}(2 ; 17)(\mathrm{q} 35 ; \mathrm{p} 13)$ and $\mathrm{t}(3 ; 8)(\mathrm{p} 13 ; \mathrm{p} 21)$ reciprocal translocation. Hum Genet. 1992;90:171-3.

55. Bruyere H, Rajcan-Separovic E, Doyle J, Pantzar T, Langlois S. Familial cryptic translocation $(2 ; 17)$ ascertained through recurrent spontaneous abortions. Am J Med Genet A. 2003;123A:285-9.

56. Estop AM, Van Kirk V, Cieply K. Segregation analysis of four translocations, $t(2 ; 18), t(3 ; 15), t(5 ; 7)$, and $t(10 ; 12)$, by sperm chromosome studies and a review of the literature. Cytogenet Cell Genet. 1995;70:80-7.

57. Sachs ES, Jahoda MG, Van Hemel JO, Hoogeboom AJ, Sandkuyl LA. Chromosome studies of 500 couples with two or more abortions. Obstet Gynecol. 1985;65:375-8.

58. Trappe R, Böhm D, Kohlhase J, Weise A, Liehr T, Essers $G$, et al. A novel family-specific translocation $t(2 ; 20)$ (p24.1;q13.1) associated with recurrent abortions: molecular characterization and segregation analysis in male meiosis. Cytogenet Genome Res. 2002;98:1-8.

Correspondence address: Ruizhi Liu, MD, Center for Reproductive Medicine and Center for Prenatal Diagnosis First Hospital, Jilin University. 71 Xinmin Street, Chaoyang District Changchun, Jilin Province 130021, China

Fax: + $8604318565-4528$ E-mail: 1rz410@126.com 